\title{
Insights from the genome of Ophiocordyceps polyrhachis-furcata to pathogenicity and host specificity in insect fungi
}

Duangdao Wichadakul ${ }^{1,2+}$, Noppol Kobmoo ${ }^{1 \dagger}$, Supawadee Ingsriswang ${ }^{1 *}$, Sithichoke Tangphatsornruang ${ }^{1}$, Duriya Chantasingh ${ }^{1}$, Janet Jennifer Luangsa-ard ${ }^{1 *}$ and Lily Eurwilaichitr ${ }^{1}$

\begin{abstract}
Background: Ophiocordyceps unilateralis is an outstanding insect fungus for its biology to manipulate host ants' behavior and for its extreme host-specificity. Through the sequencing and annotation of Ophiocordyceps polyrhachisfurcata, a species in the $O$. unilateralis species complex specific to the ant Polyrhachis furcata, comparative analyses on genes involved in pathogenicity and virulence between this fungus and other fungi were undertaken in order to gain insights into its biology and the emergence of host specificity.

Results: $O$. polyrhachis-furcata possesses various genes implicated in pathogenicity and virulence common with other fungi. Overall, this fungus possesses protein-coding genes similar to those found on other insect fungi with available genomic resources (Beauveria bassiana, Metarhizium robertsii (formerly classified as M. anisopliae s.l.), Metarhizium acridum, Cordyceps militaris, Ophiocordyceps sinensis). Comparative analyses in regard of the host ranges of insect fungi showed a tendency toward contractions of various gene families for narrow host-range species, including cuticle-degrading genes (proteases, carbohydrate esterases) and some families of pathogen-host interaction (PHI) genes. For many families of genes, O. polyrhachis-furcata had the least number of genes found; some genes commonly found in other insect fungi are even absent (e.g. Class 1 hydrophobin). However, there are expansions of genes involved in 1) the production of bacterial-like toxins in O. polyrhachis-furcata, compared with other entomopathogenic fungi, and 2) retrotransposable elements.
\end{abstract}

Conclusions: The gain and loss of gene families helps us understand how fungal pathogenicity in insect hosts evolved. The loss of various genes involved throughout the pathogenesis for $O$. unilateralis would result in a reduced capacity to exploit larger ranges of hosts and therefore in the different level of host specificity, while the expansions of other gene families suggest an adaptation to particular environments with unexpected strategies like oral toxicity, through the production of bacterial-like toxins, or sophisticated mechanisms underlying pathogenicity through retrotransposons.

Keywords: Ophiocordyceps unilateralis, Genome, Next-generation sequencing, Comparative genomics, Host specificity, Pathogenicity, Pathogen-host interaction

\footnotetext{
* Correspondence: supawadee@biotec.or.th; jajen@biotec.or.th

${ }^{\dagger}$ Equal contributors

${ }^{1}$ National Center for Genetic Engineering and Biotechnology, National

Science and Technology Development Agency, 113 Thailand Science Park,

Phahonyothin Rd., Khlong Neung, Khlong Luang 12120 Pathum Thani,

Thailand

Full list of author information is available at the end of the article
}

\section{Ciomed Central}

(c) 2015 Wichadakul et al. Open Access This article is distributed under the terms of the Creative Commons Attribution 4.0 International License (http://creativecommons.org/licenses/by/4.0/), which permits unrestricted use, distribution, and reproduction in any medium, provided you give appropriate credit to the original author(s) and the source, provide a link to the Creative Commons license, and indicate if changes were made. The Creative Commons Public Domain Dedication waiver (http://creativecommons.org/publicdomain/zero/1.0/) applies to the data made available in this article, unless otherwise stated. 


\section{Background}

Fungi constitute one of the most diverse kingdoms of living organisms including various forms and ecological roles such as decomposers, mutualists or parasitical symbionts. Their importance for industrial and agricultural applications and their experimental tractability made them useful and popular model for studying cell biology and functional genomics in various biological context. In this regard, the number of whole-genome sequence data from a wide variety of fungi has dramatically increased during the last decade [1].

Entomopathogenic fungi (or insect fungi) are also receiving growing attention with regard to the development of genomic resources. On one hand, $M$. anisopliae s.l. (including M. robertsii) and B. bassiana s.l., which are widely used as agents for biological control have instigated the development of genomic resources and experimental approaches in order to study virulence and pathogenicity $[2,3]$. On the other hand, other species such as $O$. sinensis and $C$. militaris are widely used in Asia as traditional Chinese medicine and has therefore spurred interests for studying novel biosynthetic pathway and sexual reproduction through genomic approaches $[4,5]$. Insect fungi are also well known for the production of interesting secondary metabolites such as polyketides and non-ribosomal peptides whereas the synthetic pathways have not yet been all elucidated [6].

In this study, we report a draft genome of $O$. polyrachis-furcata, a species in the $O$. unilateralis species complex, which is also a Hypocrealean entomopathogenic fungus. This species is outstanding for its ecological strategy as it modifies host ants' behavior in order to favor its own dispersion ("death grip," i.e. infected ants climb into vegetation, bite vegetal materials then hang themselves upside down until death, and considered as an extended phenotype from the fungus.) [7]. The biology of O. unilateralis still has much to be discovered. The pathogenesis and molecular basis to pathogenicity are poorly known while the molecular basis of behavior manipulation is a total black box. The genome sequencing of this species will provide a basis for further exploration on these issues.

Additionally, this fungus also differs from those previously cited regarding its host range. While $M$. anisopliae (including $M$. robertsii) and B. bassiana have very broad host ranges infecting several insect orders and could live as plant endophytes and in the soil, $O$. sinensis, $C$. militaris and $O$. unilateralis have narrower host ranges including various lepidopteran families for C. militaris [8], a family of Lepidoptera (Hepialidae) for O. sinensis [9], and only a tribe (Camponotini) in a sub-family of ants (Formicinae) for O. unilateralis [10]. Previous studies showed hidden diversity of $O$. unilateralis associated to ant species, suggesting a diversification through host specificity $[10,11]$.
A recent study suggested that $O$. unilateralis in Thailand should be subdivided into three distinct species (O. polyrhachis-furcata, O. camponoti-saundersi, O. camponotileonardi) according to the host species [11]. In this study, we focused on sequencing $O$. polyrhachis-furcata and analyzing its genes that were previously reported to be important to different steps of pathogenesis and thus virulence in other insect fungi and fungal pathogens. Through comparative genomics between our fungus and nineteen other fungi including other entomopathogenic fungi (B. bassiana, $M$. robertsii, $M$. acridum, $C$. militaris, $O$. sinensis), some fungal plant pathogens (Magnaporthe oryzae, Botryotinia fuckeliana, Fusarium graminearum, Sclerotinia sclerotiorum, Ustilago maydis, Verticillium alfalfae), opportunistic human pathogenic fungi and yeast (Aspergillus fumigatus, Candida albicans, Saccharomyces cerevisiae), a fungal pathogen of amphibian (Batrachochytrium dendrobatidis) and saprophytic fungi (Aspergillus nidulans, Neurospora crassa, Coprinopsis cinerea) as well as a non-pathogenic yeast (Schizosaccharomyces pombe); we identified genes involved in various steps of pathogenesis, investigated the common attributes of being entomopathogenic and the extent to which the host ranges have shaped their evolution as well as enable the discovery of new biosynthetic pathways.

\section{Results}

\section{General genome features}

The genome of O. polyrhachis-furcata (strain BCC54312) was sequenced in-house using the Roche 454 GS FLX system. This resulted in $1.28 \mathrm{~Gb}$ of sequence data (37x coverage) with average read length of $652 \mathrm{bp}$. The shotgun reads were de novo assembled resulting in 4419 contigs. For sequence scaffolding, a DNA library of $3 \mathrm{~kb}, 6 \mathrm{~kb}$, and $8 \mathrm{~kb}$ inserts were constructed and sent to Macrogen (Seoul, Republic of Korea) for sequencing on Hiseq2000 platform (Illumina). 4419 contigs together with the matepair libraries were assembled into 418 scaffolds (59 scaffolds > $1 \mathrm{~kb}$; N50 $3.3 \mathrm{Mb}$ ) with a total estimated genome size of about $43 \mathrm{Mb}$. The assembled genome has been deposited as an NCBI's Whole Genome Shotgun (WGS) project under accession number LKCN00000000 and the data of the sequenced samples deposited at the NCBI's BioSample database under the accession number SAMN04099149.

While having an equivalent genome size to other insect fungi (except $O$. sinensis), the genome of $O$. polyrhachis-fucata BCC54312 was predicted to have 6793 protein coding genes. This number is close to that of protein coding genes reported in [4] for O. sinensis and substantially less than those reported for $M$. robertsii, $M$. acridum, B. bassiana, and C. militaris which have broader host ranges. Furthermore, the number of secreted proteins as predicted by SignalP 4.0 [12] is less than half of those four entomopathogenic genomes (Table 1). This number is 
Table 1 Comparison of genome features among six entomopathogenic fungi

\begin{tabular}{|c|c|c|c|c|c|c|}
\hline Features & OPF & OPSINE & METANI & METACR & BEUBAS & CORMIL \\
\hline$\overline{\text { Size }(\mathrm{Mb})}$ & 43 & $\sim 120$ & 39 & 38.1 & 33.7 & 32.2 \\
\hline Coverage (fold) & $37 x(454)$ & $241 x$ & $100 x$ & $107 x$ & $76.6 x$ & $147 x$ \\
\hline No.of scaffolds(>1 kb) & 65 & - & 176 & 241 & 242 & 13 \\
\hline Scaffold N50 (Mb) & 3.3 & - & $\sim 2.0$ & 0.33 & 0.73 & 4.55 \\
\hline$\% \mathrm{G}+\mathrm{C}$ content & 45.2 & 46.1 & 51.5 & 50.0 & 51.5 & 51.4 \\
\hline$\% G+C$ in coding genes & 59.7 & - & 54.4 & 54.1 & 56.6 & 58.6 \\
\hline Protein coding genes & 6,799 & 6,972 & 10,582 & 9,849 & 10,366 & 9,684 \\
\hline Exons per gene & 3.29 & 2.6 & 2.8 & 2.7 & 2.7 & 3 \\
\hline tRNAs & $83 / 77$ & - & 141 & 122 & 113 & 136 \\
\hline No. of secreted proteins & 690 & - & 1,865 & 1,490 & $\sim 1886$ & 1,572 \\
\hline No. of $\mathrm{PHI}$ genes & 1,223 & 998 & 1,828 & 1,629 & - & 1,547 \\
\hline No. of Pth11-like GPCRs & 14 & - & 54 & 40 & 23 & 18 \\
\hline
\end{tabular}

reliable as the assembled genome was assessed to be as complete as $96 \%$ (4.5\% duplicated), $2.5 \%$ fragmented, and only $1.1 \%$ missing. The set of annotated protein coding genes was assessed to be $95 \%$ complete $(9.2 \%$ duplicated), $2.8 \%$ fragmented, and only $1.8 \%$ missing.

Table 1 shows the overall genome features of $O$. polyrhachis-furcata compared with other five entomopathogenic fungi using the same versions of computer programs and databases except for protein secretion. A phylogenomic tree based on conserved proteins among all taxa used in this study showed O. polyrhachis-furcata to be closely related to $O$. sinensis which is from the same family (Ophiocordycipitaceae) and clustered with other fungi from the order Hypocreales including other entomopathogenic fungi (Fig. 1).

\section{Pathogen-Host Interaction genes}

The potential virulence-associated genes in the $O$. polyrhachis-furcata and nineteen other genomes were identified by BLAST analysis against the pathogen-host interaction (PHI) database [13]. This is a useful database synthesizing a plethora of experimentally verified genes related to the mediation of fungal pathogens, including Oomycetes, to cause disease and to provoke response from the hosts (pathogenicity, virulence and effector genes). We identified 1890 putative PHI genes in $O$. polyrhachis-furcata, which is remarkably lower than in other insect fungi with broader host ranges (see Additional file 1: Table S1). The six species of entomopathogenic fungi were clustered together according to the number of specific PHI genes, shown to be related to pathogenicity, which were identified across all the genomes used for the analysis (Fig. 2). Particularly, O. polyrhachisfurcata was the closest to O. sinensis. Also, the plant pathogens appeared close in terms of PHI genes abundance while yeasts (S. cerevisiae, S. pombe, C. albicans), saprophytic mushroom (C. cinerea) and the amphibian pathogen $(B$. dendrobatidis) share similar patterns of PHI genes abundance (Fig. 2 and Additional file 1: Table S1).

Although O. polyrhachis-furcata and O. sinensis have generally less PHI genes compared with the other insect fungi, some PHI gene families were specifically found or in higher numbers in these two fungi. Interestingly, $O$. polyrhachis-furcata contains more PHI:871 genes (8), compared with other five entomopathogenic fungi (0 to $1)$. This class of genes was reported as virulence gene in the rice blast fungus, $M$. grisea [14]. Among the twenty genomes, all except $O$. polyrhachis-furcata and M. grisea, contain at most two PHI:871 genes. Among the six entomopathogenic fungi, PHI:113, PHI:1158, PHI:1276, PHI:2314, PHI:449 and PHI:1278 genes were found only in O. polyrhachis-furcata. PHI:113 was also reported in M. grisea. Its disruption caused the loss of pathogenicity against rice [15]. PHI:1158 was characterized in Mycosphaerella graminicola as resistance to azole fungicides [16]. The gene deletion of PHI:2314 resulted in reduced virulence of $S$. sclerotiorum and oxidative burst in adjacent uninfected cells of tomato (Nicotiana benthamiana) [17]. The disruption of PHI:449 gene in Claviceps purpurea T5 reduced virulence against Rye [18] while the disruption of PHI:1276, PHI:1278 in Gibberella zeae did not affect pathogenicity [19]. O. polyrhachis-furcata and O. sinensis contain PHI:292 [20], PHI:2198 [21], PHI:2222 [22], PHI:2342 [23] and PHI:2534 [24] genes, which are missing from the other four entomopathogenic fungi. The deletion of all of these genes except $\mathrm{PHI}: 2342$ resulted in reduced-virulence phenotypes in other fungal pathogens. For example, the lethality effect on A. fumigatus Af293 comes from the double mutant of PHI:2534 (the deletion of both ERG11A and ERG11B) while each individual deletion can compensate the loss of the other [24].

B. bassiana contain more copies of PHI:1139 (79), PHI:820(23), PHI:821(19), PHI:823 (10), compared to 


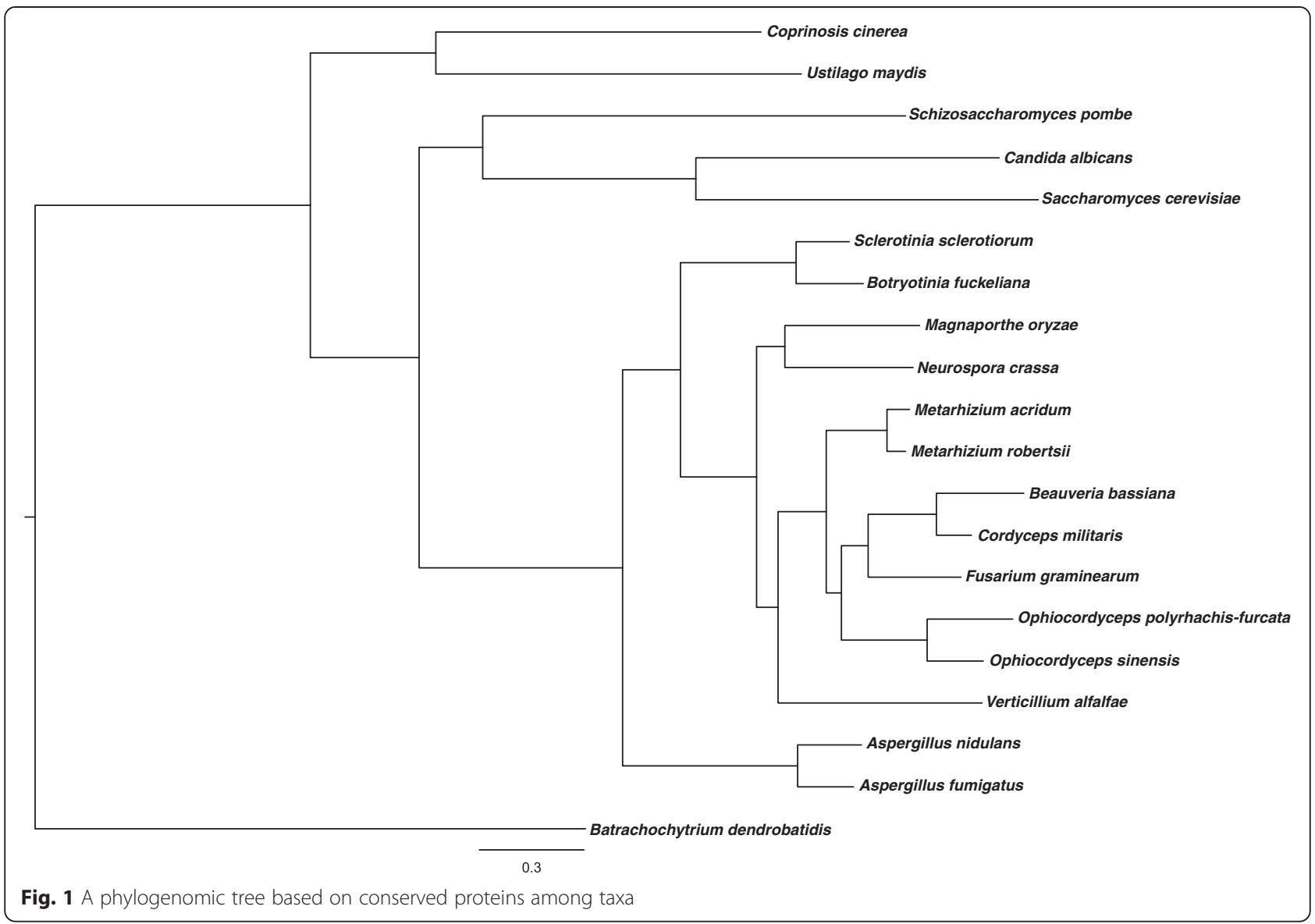

other five entomopathogenic fungi (5-15 for PHI:1139 and 1-2 for PHI:820, PHI:821, and PHI:823). Interestingly, PHI:1139 in Xanthomonas oryzae is a plant avirulence determinant [25]. The mutant phenotype of other three PHI genes is resistant to chemical fungicides [26-28].

Another interesting PHI genes set consists of PHI:2240, PHI:1555, PHI:812, and PHI:511 as O. polyrhachis-furcata and $O$. sinensis have less number of these PHI genes compared to other four entomopathogenic fungi. PHI:2240 was reported as a plasma membrane-localized sucrose transporter (Srt1); a fungal virulence factor, characterized from corn smut fungus $U$. maydis [29]. PHI:1555 has not been reported to affect pathogenicity while PHI:812 was reported as a virulence gene in M. grisea [14]. Finally, PHI:511 was reported as involving in drug sensitivity and virulence in $C$. albicans [30] (see Additional file 2: Table S2).

\section{Surface adhesion genes}

The first step to cause disease is the attachment of the infective propagules on the hosts'surface. This involves hydrophobic interactions between the spore surface proteins (e.g. adhesin, hydrophobin) and the lipid layer on the epicuticle of insects. Hydrophobins can be classified into two classes based on their hydropathy and solubility characteristics [31]. In insect fungi, hydrophobins were previously shown to be involved in the formation of appressorium in $M$. anisopliae [32] and B. bassiana [33, 34] as well as virulence factors in M. brunneum [35]. Only Class 2 hydrophobins, which are represented by the orthologous proteins MAA_01182 and MAC_09507 in M. robertsii and $M$. acridum respectively, were identified in the genome of O. polyrhachis-furcata. The genomes of the three other entomopathogenic fungi also contain this class of hydrophobins. In addition, six other species (B. fuckeliana, $F$. graminearum, $M$. oryzae, $N$. crassa, S. sclerotiorum and $V$. alfalfae) have orthologous proteins of this class. Notably, the protein BBA_03071 of B. bassiana, which is annotated as Hydrophobin-like protein at UniProt, was clustered to the same orthologous group of the Class 2 hydrophobins of the other entomopathogenic fungi while the annotated Hydrophobin 2 of this species (BBA_00530: hyd2) could not be clustered with the other species. The gene product of hyd2 was reported as the major component of the $B$. bassiana rodlet layer [33]. In contrast, no orthologous Class 1 hydrophobin was identified in $O$. polyrhachis-furcata. The Class 1 hydrophobins MAA_10298 and MAC_04376, reported in [2], and BBA_03015, reported in [3], were identified in C. militaris and O. sinensis as well as in eight other 




Fig. 2 A phylogram based on the number of genes in all $\mathrm{PHI}$ families with presence/absence of some selected families. OPF = Ophiocordyceps polyrhachis-furcata, OPSINE = Ophiocordyceps sinensis, BEUBAS = Beauveria bassiana, CORMIL = Cordyceps militaris, METANI = Metarhizium anisopliae, METROB = Metarhizium robertsii, FUSGRA = Fusarium graminearum, VERALB = Verticillium alfalfae, $S C L S C L=$ Sclerotinia sclerotiorum, BOTFW = Botryotinia fuckeliana, ASNIA = Aspergillus nidulans, $\mathrm{ASF}=$ Aspergillus fumigatus, $\mathrm{SACCES}=$ Saccharomyces cerevisiae, CANAIB = Candida albicans, SCHIPO= Schizosaccharomyces pombe, COPCIN = Coprinosis cinerea, USTMAY = Ustilago maydis, BATD = Batrachochytrium dendrobatidis species, including A. fumigatus, A. nidulans, B. fuckeliana (strain BcDW1), C. cinerea (strain Okayama-7/130/ATCC MYA-4618/FGSC 9003), Gibberella zeae/F. graminearum (anamorph), M. oryzae, S. sclerotiorum, U. maydis.

Beside hydrophobins, the MAD1 adhesin (MAA_03775), characterized previously in $M$. robertsii, also provides adhesion specifically to insect host surfaces, enhances the expression of genes related to i.e., germination, blastospore formation, and thus affects virulence to caterpillars [36]. $O$. polyrhachis-furcata as well as all other eighteen species have multiple orthologous proteins of this adhesin. The MAD2 adhesin (MAA_03807) allows adhesion of $M$. robertsii to plant surfaces [36] but has no effects on fungal differentiation and entomopathogenicity. Interestingly, only six genomes, the $V$. alfalfae genome together with five other from entomopathogenic fungi, excluding $O$. sinensis have a single copy of MAD2 adhesin ortholog.

\section{Insect cuticle degrading genes}

Insect pathogens are expected to secrete large number of enzymes for degrading insect cuticle. These include various proteinases, particularly subtilisins, and other enzymes susceptible to degrade molecules present on the insects' cuticles (i.e. chitinase and other glycoside hydrolases). O. polyrhachis-furcata and O. sinensis contain similar numbers of subtilisins, trypsins, and aspartyl proteases which are much smaller than those of other four entomopathogenic fungi (Additional file 3: Table S3 and Fig. 3a). In $M$. anisopliae s.l., subtilisins were reported to degrade host cuticles and allow acquiring nutrients, with potential functional differences between subfamilies in secondary substrate specificities and adsorption properties [37]. O. polyrhachis-furcata, O. sinensis and C. militaris contain about half the number of subtilisins (S08) compared with B. bassiana, M. robertsii, and M. acridum. Eleven out of twenty-three subfamilies of subtilisins, were not identified in any of the six entomopathogenic species while four are common across all six species (Additional file 4: Table S4). Among those that were commonly found in the six insect fungi, subfamily S08.UPA (subfamily S8A unassigned peptidases) is very abundant.

Regarding the subtilisins S53 (sedolisins), four out of five subfamilies could be identified in entomopathogenic fungi. $O$. polyrhachis-furcata and O. sinensis contain only one protease in the subfamily S53.UPW (family S53 unassigned peptidases), which is common across the six entomopathogenic fungi. Four other entomopathogenic species contain a few more proteinases, including aorsin (S53.007) and grifolisin (S53.010) with one additional scytalidolisin (S53.011) for C. militaris, which were not found in O. polyrhachisfurcata and O. sinensis. The subfamily S53.003 (tripeptidylpeptidase I) was not identified in any six species.

The subtilisins (S08 and S53) of O. polyrhachis-furcata derived from those of other entomopathogenic fungi do 

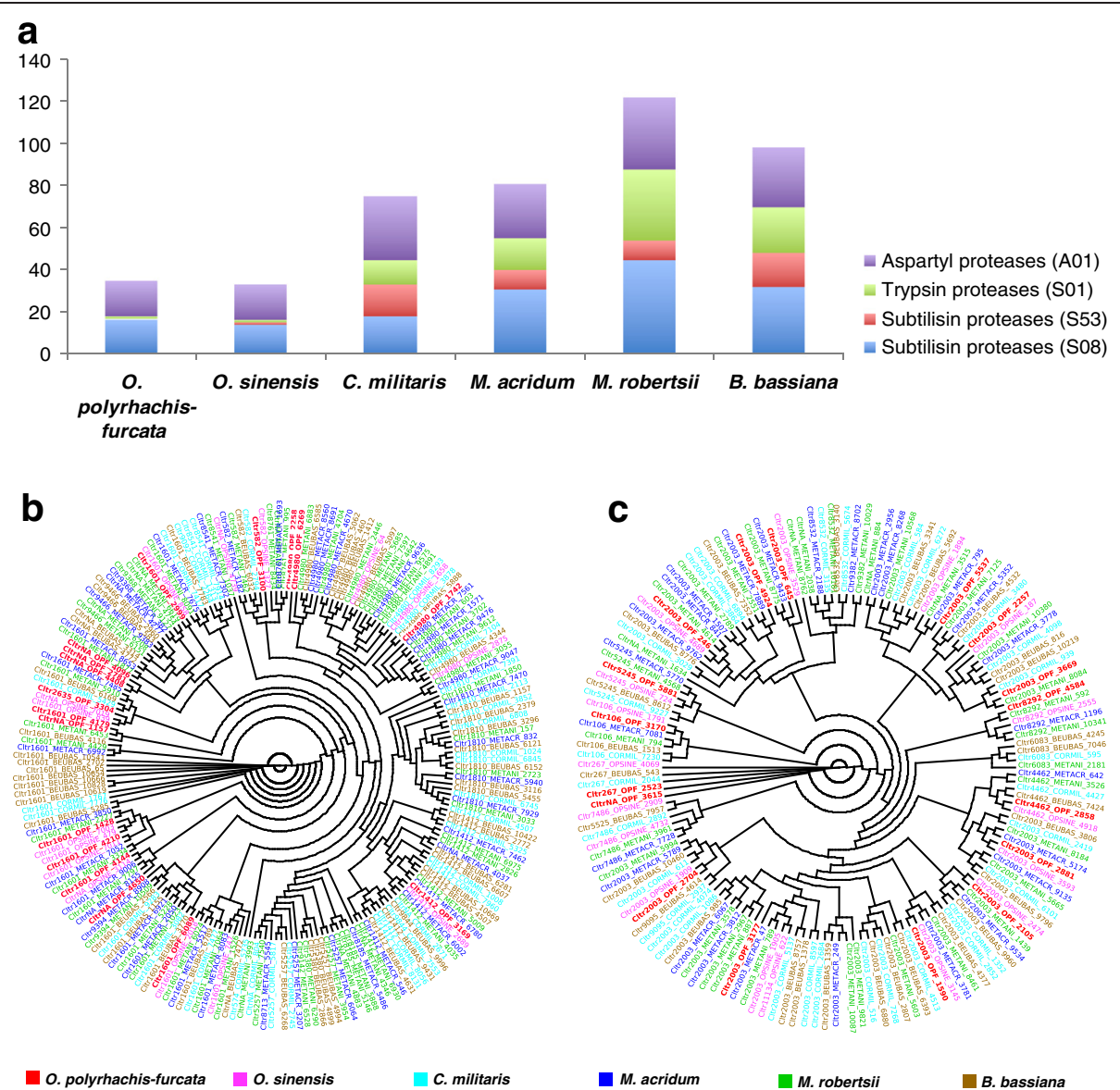

Fig. 3 Expansions of proteases among six entomopathogenic fungi including O. polyrhachis-furcata. a The distribution of proteases families among the six entomopathogenic fungi included in this study. $\mathbf{b}$ A maximum likelihood-based unrooted phylogenetic tree illustrating the relation between orthologous proteins of subtilisins (S08 and S53). c A maximum likelihood-based unrooted phylogenetic tree illustrating the relation between orthologous proteins of aspatyl proteases (A01). The sequences labels; colored following insect fungi species: red = O. polyrhachis-furcata $(\mathrm{OPF})$, brown $=$ B. bassiana $(\mathrm{BEUBAS})$, green $=$ M. robertsii $(\mathrm{METANI})$, dark blue $=M$. acridum $(\mathrm{METACR})$, light blue $=C$. militaris $(\mathrm{CORMIL})$, pink $=0$. sinensis (OPSINE); are written in the form of cluster id._fungal species_sequences id. The cluster identities were obtained inferred according to Inparanoid/ QuickParanoid [38, 39]

not form a monophyletic clade (Fig. 3a), indicating that they have evolved independently from the subtilisins of other entomopathagenic fungi. Five of them (OPF_4096, OPF_2781, OPF_4408, OPF_1157, OPF_4650) could not be assigned to any orthologous group with any other fungi. These proteins were respectively annotated as S08.053 (MER006091:oryzin) (Aspergillus flavus), S08.UPA (MER032872: subfamily S8A unassigned peptidases) (M. grisea), S08.053 (MER087525:oryzin) (Aspergillus clavatus), S08.056 (MER126013:cuticle degrading peptidase of parasitic fungus) (Hirsutella minnesotensis), and S08.056 (MER123475:cuticle degrading peptidase of parasitic fungus) (O. sinensis). However, it is to be noted that orthologous groups of subtilisins inferred by Inparanoid/ QuickParanoids [38, 39] are not supported by the maximum likelihood-based phylogenetic inference (Fig. 3), suggesting that the similarity-based method of Inparanoid/QuickParanoid should be taken with caution.
Both O. polyrhachis-furcata and O. sinensis contain only one trypsin S01.UPB (subfamily S1B unassigned peptidases), which is conserved across six entomopathogenic fungi. Other insect fungi species have substantially higher number of trypsins (22 in B. bassiana, 34 in M. robertsii, 15 in $M$. acridum and 12 in C. militaris). Subfamily S01.UPA (subfamily S1A unassigned peptidases) was identified in all but the two Ophiocordyceps and the most abundant family. Subfamily S01.412 (CHY1 peptidases or chymotrypsins) was identified in B. bassiana (BBA_02727), C. militaris (CCM_08282) and $M$. robertsii (MAA_07484) but not in M. acridum. Additionally, only B. bassiana contains additional two Nma111 peptidases (S01.434).

The numbers of aspartyl proteases (A01) identified in $O$. polyrhachis-furcata and O. sinensis are about half of the other four entomopathogenic fungi and in only four out of thirty-five subfamilies. Subfamily A01.UPA (subfamily A1A unassigned peptidases) is conserved across the six 
species and very abundant. Twenty-two out of thirty-five subfamilies were not identified in any six species. Subfamilies A01.018 (saccharopepsin) and A01.077 (CtsD peptidase) were found in all but the two Ophiocordyceps species. Several subfamilies A01.017 (endothiapepsin), A01.027 (trichodermapepsin), A01.057 (MernameAA034 peptidase), A01.079 (PepAa peptidase), and A01.UPB (subfamily A1B unassigned peptidases) were identified in only the two Metarhizium species. Additionally, A01.082 (SA76 peptidase) was identified in all except $O$. sinensis (Additional file 4: Table S4). Like subtilisins S08 and S53, the aspatryl proteases of $O$. polyrhachis-furcata do not form a monophyletic clade (Fig. 3b).

Like proteases, chitinases have been reported as involved in host penetration which is a crucial first step of pathogenesis and to influence the virulence [40-42]. The chitinases are classified into a family of Glycoside Hydrolase (GH18). GH18 is the most abundant family of Glycoside Hydrolase found in all fungi included in our analysis (Additional file 5: Table S5). Among entomopathogenic fungi, broad host-range species including $B$. bassiana and $M$. robertsii also possess more genes encoding this GH family (195 and 179 respectively) than M. acridum (160), C. militaris (157), O. sinensis (110) and also O. polyrhachis-furcata (134). Additionnally, $O$. polyrhachis-furcata and O. sinensis have less proteins of several GH families than the other four entomopathogenic fungi (GH16, GH3, GH4, GH76, GH92, GH43, GH78, GH79: Additional file 5: Table S5). Some GH, and Polysaccharide Lyase families were reported to be related to hostspecific adaptation in plant pathogens (i.e. GH6, GH7, CBM1, GH28, GH78, GH88, GH95, PL1, PL3 [43]). All six entomopathogenic fungi do not have the $\mathrm{GH} 7$ families, less than half of the numbers of GH28, GH78, GH95 (Additional file 5: Table S5), and many less or no PL1 and PL3 (Additional file 6: Table S6). Among these families; GH28, GH78 showed the same tendency as that found for GH18 in that broad host-range species possess more genes than narrow host-range species including $O$. polyrhachis-furcata. Regarding the families of carbohydrate esterases (CE), on one hand, O. polyrhachis-furcata and $O$. sinensis have less number of $\mathrm{CE}$ for the families CE1 and CE6, compared to the other four entomopathogenic fungi species. On the other hand, they contain similar number of proteins to the other insect fungi but different to plant pathogens for the CE3, CE5 and CE12 families (Additional file 7: Table S7).

\section{Bacterial-like toxins}

Entomopathogenic fungi are expected to infect hosts through cuticular penetration and thus to possess less toxins compared with other pathogens such as bacteria or viruses. However, the number of bacterial-like toxin proteins and toxin-biosynthesis proteins found in
O. polyrhachis-furcata are relatively high (22), compared to C. militaris (9), M. robertsii (34), M. acridum (10) and $O$. sinensis (9); this number is actually the same as B. bassiana [3] (Additional file 8: Table S8). M. robertsii has the highest number of such proteins (34). Seventeen out of twenty-two toxins found in the genome of $O$. polyrhachis-furcata are heat-labile enterotoxins A chain. Others include a zeta toxin, a ribotoxin, two cholera entorotoxins and a killer toxin. Among these toxins, a gene putatively encoding a heat-labile A chain was identified in front of a NRPS gene in a predicted NRPS gene cluster. The prevalence of genes coding for bacterial-like toxins in the genome of $O$. polyrhachis-furcata suggests the possibility of oral toxicity as a mode of killing insect host.

\section{Signal transduction}

The encounter between the pathogens and the hosts will inevitably engage the signal transduction from both parties. We also found in the genome of $O$. polyrhachis-furcata various genes related to cellular signal transduction including $\mathrm{G}$ proteins, G protein-coupled receptors (GPCRs) and histidine kinases (HK).

Among six entomopathogenic fungi, O. polyrhachisfurcata contains the smallest number of Pth11-like Gprotein coupled receptors (GPCRs) which are cell-surface integral membrane proteins required for pathogenicity [44]. Also, as PHI genes (PHI-base accession: PHI:404 and PHI:441), they mediate cell response to inductive cues [45]. PHI genes were shown to be related to host specificity of M. acridum via differential expression on locust and cockroach cuticles [2]. All other fourteen nonentomopathogenic fungi clearly contain less number of Pth11-like genes.

Two PHI:441 proteins in O. polyrhachis-furcata out of seven, OPF_8495 (PHI:441|BTP1|CAE55153|TX:40559|Botrytis cinerea) and OPF_6721 (PHI:441|BTP1|CAE5 5153|TX:40559|Botrytis cinerea), have no orthologs with any other nineteen compared species. Based on BLASTX against NR database, the two proteins were annotated as "hypothetical protein THITE_2110904" and "putative integral membrane protein [Eutypalata UCREL1]". Meanwhile, six putative PHI:404 genes were found in O. polyrhachis-furcata and could be clustered into orthologous groups with the other fungi.

G protein alpha subunits have been comprehensively studied, as a key component of signal transduction pathways and pathogenicity [46]. Its disruption in Stagonospora nodorum made the fungus less pathogenic, unable to sporulate, and albino phenotype with secretion of brown pigments into growth media [47]. In Metarhizium, G-alpha proteins in $M$. robertsii (MAA_03488) and M. acridum (MAC_04984) were observed as the most expressed G-alpha genes during their infection of either cockroach or locust cuticles [2]. These two genes are clustered together 
as orthologous proteins with all remaining eighteen species including O. polyrhachis-furcata: OPF_3427. The two-component Histidine Kinase (HK) signaling pathways mediate environmental stress responses and regulation of secondary metabolism $[48,49]$, response to bacterial metabolites [50], hyphal development [51], virulence [52] and sensitivity to dicarboximide and phenylpyrrole fungicides $[53,54]$ in diverse fungal species. O. polyrhachis-furcata contains the similar number of histidine kinases (9) compared with M. robertsii (10) and M. acridum (9) reported in [2].

\section{Core genes involved in the biosynthesis of secondary metabolites}

Insect fungi are also well known for producing a variety of secondary metabolites. Genes implicated in their biosynthesis have received large attention, particularly polyketides and non-ribosomal peptides synthetases (PKS and NRPS) [6]. Based on SMURF [55], the O. polyrhachisfurcata genome encodes 4 putative NRPS, other 4 NRPSlike, 14 PKS, 1 PKS-like, 1 NRPS-PKS hybrid and without dimethylallyl tryptophan synthase (DMAT) genes (Table 2). The total number of 24 core genes in this species is much less than that of $M$. robertsii (60) and M. acridum (42) [2] and somewhat less than that of B. bassiana (36) [3] and also $C$. militaris (28) [5]. Similar to $M$. robertsii, one of the four putative NRPS-like genes in O. polyrhachis-furcata is an antibiotic synthetase, reported for preserving the cadaver from microbial competitors [2]. Another NRPS-like protein (OPF_1123) is mostly similar to another antibiotics synthase (Linear gramicidin synthase subunit D of $F$. oxysporum). The unique PKS/NRPS hybrid gene gets the top hit to fusarin $\mathrm{C}$ cluster-polyketide synthase/NRPS, which is a mycotoxin produced by several Fusarium species with carcinogenic effects [56]. Beside these core genes, three additional genes (fus2, fus8, and fus9), reported to be responsible for fusarin production [57], were also identified within this hybrid cluster. O. polyrhachis-furcata possesses an NRPS (OPF_4495), which is similar (39\% identity) to peramine synthetase (PerA) of Epichloe festucae, the essential enzyme for the biosynthesis of peramine; a compelling insect feeding deterrent to protect their grass host from insect herbivory [58]. Based on antiSMASH [59], O. polyrhachis-furcata also possesses the PKS-like and NRPS-like which are respectively similar to Ochratoxin A polyketide synthase (35\% identity) and a non-ribosomal peptide synthetase (36 \% identity) of Penicillium nordicum characterized in [60]. Even located on the same scaffold, they are not on the same cluster.

\section{Repeat elements and transposases}

On one hand, the genome of $O$. polyrhachis-furcata comprises notably more Class II transposable elements (TEs) - the DNA transposons including DNA/hAT (23), DNA/Mariner (7), DNA/MuDR (11), and DNA/Helitron (7) - compared with the genomes of $C$. militaris and $M$. acridum which contain less than five of these elements in their genomes. On the other hand, O. polyrhachisfurcata possess less of these elements compared to the genomes of $B$. bassiana and $M$. robertsii (Fig. 4 and see Additional file 9: Table S9) except for DNA/Helitron of which $B$. bassiana is devoid. Particularly, $M$. robertsii contains several more DNA/Helitron (26) compared with O. polyrhachis-furcata (9) and M. acridum (5) while $C$. militaris do not have this specific element. Regarding the Class I elements or the retroelements, the

Table 2 Number of core genes involved in the biosynthesis of secondary metabolites

\begin{tabular}{|c|c|c|c|c|c|c|c|}
\hline Fungi & DMAT & HYBRID & NRPS & NRPS-like & PKS & PKS-like & Total \\
\hline O. polyrhachis-furcata & 0 & 1 & 4 & 4 & 14 & 1 & 24 \\
\hline C. militaris & 1 & 3 & 5 & 8 & 9 & 2 & 28 \\
\hline M. acridum & 3 & 1 & 13 & 8 & 13 & 4 & 42 \\
\hline M. robertsii & 5 & 5 & 14 & 9 & 24 & 3 & 60 \\
\hline B. bassiana & 0 & 3 & 13 & 7 & 12 & 1 & 36 \\
\hline B. cinerea & 1 & 0 & 6 & 8 & 16 & 6 & 37 \\
\hline S. sclerotiorum & 1 & 0 & 5 & 5 & 16 & 2 & 29 \\
\hline F. graminearum & 0 & 1 & 10 & 11 & 14 & 1 & 37 \\
\hline E. festucae & 4 & 1 & 18 & 9 & 11 & 3 & 46 \\
\hline N. crassa & 1 & 0 & 3 & 3 & 6 & 2 & 15 \\
\hline M. oryzae & 3 & 3 & 5 & 6 & 12 & 3 & 32 \\
\hline A. nidulans & 6 & 1 & 11 & 12 & 24 & 4 & 58 \\
\hline A. fumigatus & 7 & 1 & 13 & 5 & 13 & 1 & 40 \\
\hline
\end{tabular}

This table is extended and rearranged from Table S13 in [2] by adding O. polyrhachis-furcata's identified core genes following SMURF [55]. Core genes of $C$. militaris and $B$. bassiana were excerpted from Table 3 in [5] and Table 2 in [3], respectively. DMAT: Dimethylallyl tryptophan synthase, NRPS: non-ribosomal peptide synthetase, HYBRID, hybrid PKS-NRPS enzyme 




Fig. 4 The numbers of transposases between the genomes of different entomopathogenic fungi. The data of 0 . sinensis [4] were not included in this graphic as this species contain much higher numbers of most transposable elements classes (Additional file 9: Table 59) and skewed the representation

LTR/Copia, LTR/Gypsy, as well as the Non-LTR/LINE are much more abundant in O. polyrhachis-furcata compared to those species. Nevertheless, except for DNA/hAT and DNA/helitron, O. sinensis contain many more transposable elements than the other insect fungi species studied here (Additional file 9: Table S9). Transposases were reported to be expressed during infection in Metarhizium [2]. Therefore, this type of genomic mobile element may be related to pathogenicity.

\section{Discussion}

We present here a genome draft of an outstanding insect fungus, O. unilateralis s.l. from the host Polyrhachis furcata. In our study, we compare this genome to other available fungal genomes of various origins in order to gain insights into the biology of this species. The particularity of this fungus is its extreme hostspecificity as shown by the fact that different species are associated to different ant species $[10,11]$. Here, we have sequenced $O$. polyrhachis-furcata which is specific to an ant species while, for the others, the degree of host range is variable, ranging from families of the same insect orders (e.g. O. sinensis and O. militaris) to several insect orders (e.g. B. bassiana, M. robertsii).

We found that the genome of $O$. polyrhachis-furcata contains various genes which were shown to be implicated during the pathogenesis of fungal pathogens. Many of them are in common with other entomopathogenic fungi and fungal plant pathogens.

In this genome, we observed contractions of several kinds of genes, compared to broad host range entomopathogenic fungi. This signature of genes contraction is found for genes involved throughout the pathogenesis, from genes required for the adhesion of infective propagules to the synthesis of metabolites potentially necessary for coping with insect immune systems. This may have critical implications in the life of this fungus. For example, hydrophobins Classes 1 and 2 are amphiphilic proteins, mostly involved in the mediation of the contact between the fungal cells and hydrophobic/hydrophilic surfaces. Although the roles of both classes and different paralogs are not yet totally elucidated and partially overlapping [31], the disruption of a number of hydrophobins resulted in altered hydrophobicity of the mycelia as well as the morphology and production of conidia [3335]. The absence of hydrophobin Class 1 in $O$. polyrhachis-furcata could be related to fastidious growth and sporulation of this species in standard complex media while B. bassiana, M. spp., C. militaris and $O$. sinensis are all fast growers and can produce spores abundantly in the laboratory.

Comparison with extensive available fungal genomes allowed us to grasp common aspects and differences between plant and insect pathogens. A notable difference is the absence of MAD2 adhesin in plant pathogens, which is not the case for the entomopathogenic fungi except $O$. sinensis. This suggests that the entomopathogenic fungi may have dual ways of life, being parasitic to insects and in the same time having the capacity to be endophytes in plants. This has already been shown in $B$. bassiana and $M$. anisopliae [61, 62]. The absence of MAD2 in plant pathogens suggests a totally different mechanism of adhesion. Furthermore, notable differences in numbers of genes are found for various Glycoside Hydrolase (GH), Carbohydrate Esterase (CE) families as well as Polysaccharide Lyase (PL) families. Overall, the comparative analysis shows a cleavage between insect and plant pathogens in the penetration of host's cell. This may be linked to the fact that fungal pathogens of plants need to overcome the cell wall which has different biochemical composition to insect cuticle.

Subtilisin proteases have been shown to play crucial role in regulating the specificity to hosts of entomopathogenic 
fungi via the reduction of isoforms [37] or the differential expressions of isoforms according to substrates [63]. Hosts play important role in the evolution of subtilisin-like proteases in entomopathogenic fungi by imposing constraints into the realized niches in vivo. In Metarhizium, generalist strains were shown to have more paralogous isoforms than a specialist strain [37]. According to our comparative analysis, there is also a tendency in the reduction of subtilisins proteases genes for narrow-host range species of insect fungi with $O$. polyrhachis-furcata having in effect the narrowest host range and one of the lowest numbers of genes coding for subtilisins proteases compared with the other entomopathogenic fungi. This is in accordance with the pattern of the reduction in genes number, found in $\mathrm{GH}$ and $\mathrm{CE}$ as well as in other genes coding for cuticledegrading proteolytic enzymes like trypsin and aspatyl proteases, for narrow-host range species. This suggests a direct association between host range and diversity of cuticle-degrading enzymes. Altogether, this consistently supports the early host recognition events as key to host specificity and the tendency toward reduced genes numbers associated with narrow host range.

Referred to the PHI genes classification, we observed also that $O$. polyrhachis-furcata and $O$. sinensis had substantially less genes for some families when compared to the other entomopathogenic fungi. One of these families is clearly related to the membrane transport of sucrose (PHI:2240). The difference in number of genes for this family may result from the affinity to different nature of carbon sources in different insect hosts. Another family of PHI genes (PHI:511), which has different numbers of genes between $O$. polyrhachis-furcata/O. sinensis and the broad host range species, is involved in drug sensitivity. Systemic immune response in different hosts may influence on the evolution of this family of genes in entomopathogenic fungi. Other families of PHI genes showing substantial reduction of gene numbers in $O$. polyrhachis-furcata are PHI:404 and PHI:441 which are also Pth11-like G-protein coupled receptors (GPCRs) previously shown to be related to host specificity. $O$. polyrhachis-furcata has the lowest number of Pth11-like genes compared to other five entomopathogenic fungi.

The genes contraction in these various families suggest that specific species like O. polyrhachis-furcata may have lost a plethora of proteins of these particular families which potentially cope with diverse systemic immune responses from unspecific host.

An unexpectedly high number of genes related to biosynthesis of bacterial-like toxins are found in the genome of $O$. polyrhachis-furcata, compared to other entomopathogenic fungi species considered as having narrow host range $(M$. acridum, C. militaris). Previously, comparative genomics between generalist and specialist strains in $M$. anisopliae s.l. (subsequently $M$. robertsii and M. acridum) [64] indicated that specialists had reductive evolution of genes involved in toxin biosynthesis, suggesting that they had lost the capacity to kill host rapidly and to exploit host saprotrophically. Instead, they got specialized into strategies optimizing the struggle against host immune system and exploitation of living hosts. Furthermore, our comparative analysis also supports this hypothesis regarding $M$. robertsii and M. acridum which differ in their host ranges and diversity of putative genes producing toxins. Therefore, we expect $O$. polyrhachis -furcata which is an extreme specialist to have evolved into the latter strategy while the data support for the former. This suggests that $O$. unilateralis may have a totally different mechanism for killing host from that of $M$. anisopliae. Toxins found in O. polyrhachis-furcata's genome are for many enterotoxins, suggesting that oral toxicity may constitute a mode of killing for our fungus. However, how $O$. polyrhachis-furcata, as a species of $O$. unilateralis which is well documented for its extended phenotypes in manipulating the ant host, strives to compromise between rapid killing by toxin and slow killing enabling the host manipulation remains to be solved.

Another distinctive feature of O. polyrhachis-furcata's genome is the composition of transposable elements. The LTR/Copia and LTR/Gypsy are much more abundant in O. polyrhachis-furcata than in the other insect fungi except $O$. sinensis which has the highest numbers of transposable elements of almost all classes. It is well known that transposable elements are important source of genetic variability of different species and also contribute to intra-specific diversification in various fungi [65]. Also, transposable elements were shown to have important roles in pathogenicity and virulence for many microorganisms. Particularly, retrotransposons were shown be involved in the pathogenicity of C. albicans [66] and associated with the rapid evolution of effectors and the adaptation to new host in other pathogenic filamentous fungi [67] and Oomycetes [68]. For insect fungi, it was shown that more than $65 \%$ of the transposase genes were transcribed in Metarhizium hyphae during the infection process [2]. Therefore, the enrichment of retrotransposons in O. polyrhachis-furcata and $O$. sinensis could be related to their high host specificity and a unique pathogenicity compared to the other insect fungi. The evolution of host specificity and the diversification of insect fungi may thus be driven by the expansion/reduction of these elements.

\section{Conclusions}

The sequencing and annotation of fungal genomes have allowed mycologists to gain insight into the fundamental aspects of fungal and eukaryotic biology. Comparative analyses between $O$. polyrhachis-furcata and some other fungi give unprecedented insights into the biology of this species, particularly regarding the emergence of its 
extreme host specificity. Gene contractions have been postulated as being one of major causes in the evolution of host-specificity in various organisms. This is due to the fact that losses of genes are accompanied by losses of capacity of the organisms to exploit range of hosts. The contraction of various gene families in O. polyrhachis-furcata is in line with this hypothesis. However, this cannot alone explain the evolution of host specificity. Specific genes and even genomic regions or chromosomes are also the origin of host specificity in many fungal pathogens. Some genes found in $O$. polyrhachis-furcata are unique among entomopathogenic fungi. The contribution of these genes to the unique biology and host specificity of $O$. unilateralis s.l. remains to be studied. Particularly, the expansions of genes related to the production of bacterial-like toxins and of retrotransposons are of major interests. While loss of toxins and capacity to kill hosts rapidly was proposed as on mechanism underlying host-specificity [64], the pattern of expansion observed in O. polyrhachis-furcata suggest a completely different mechanism. Also, the expansion of retrotransposons in this fungus is unique among insect fungi. These findings will pave a way to a better understanding of this unique organism and provide promising field of research.

\section{Methods}

\section{Fungal strains}

O. polyrhachis-furcata (BCC54312) was collected from Khao Yai National Park in Nakhon Ratchasima province of Thailand. The strain was isolated and grown on Grace Insect Cell Medium and PDA according to [69]. After the growth on PDA for two months, the mycelia were harvested separated into several eppendorfs, not to exceed approximately $100 \mathrm{mg}$ per tube. The mycelia were extracted for DNA by DNeasy Plant Mini Kit (QIAGEN) by following the manual for 454 sequencing and also using a modified CTAB extraction for samples aimed for mate-pair sequencing.

\section{Genome/transcriptome sequencing and assembly}

The genomic DNA sample of Ophicordyceps polyrhachisfurcata was extracted and used to construct shotgun genomic DNA library according to the GS FLX protocol (Roche). The shotgun reads were de novo assembled by Newbler v.2.8. In order to construct scaffolds, the genomic DNA sample was used to construct mate-pair libraries with varied insertion sizes of 3, 6 and $8 \mathrm{~kb}$ sequencing which were sequenced on Hiseq2000 (Illumina). The mate-pair reads together with the pre-assembled contigs were then used for scaffolding using SSPACE 2.0 [70].

To obtain the transcriptome, O. polyrhachis-furcata (BCC54312) was grown on four different media formulations: PDA, PDA + Bacto Soytone $1 \%$, PDA + Malt Extract $0.5 \%$ and PDA + Phyto Peptone $2 \%$. The mycelia from different media were harvested together and frozen with liquid nitrogen until the RNA extraction. Frozen mycelia were grinded and transferred to $2.0 \mathrm{ml}$ tubes. $1 \mathrm{ml}$ of RNA extraction reagent (Invitrogen) was added to each tube, vortexed and added $0.1 \mathrm{ml} 5 \mathrm{M} \mathrm{NaCl}$ and $0.3 \mathrm{ml}$ Chloroform. The solutions were then centrifuged at $14,000 \mathrm{rpm}$ for $5 \mathrm{~min}$ at $4{ }^{\circ} \mathrm{C}$. The supernatants were then transferred to new tubes and added equal volumes of Chloroform $(\sim 1 \mathrm{ml})$, vortexed and centrifuged at $14,000 \mathrm{rpm}$ for $10 \mathrm{~min}$ at $4{ }^{\circ} \mathrm{C}$. The chloroform extraction was repeated until there was not interphase anymore. The RNA was precipitated with cold ethanol and $3 \mathrm{M} \mathrm{LiCl}$, incubated at $-20{ }^{\circ} \mathrm{C}$ overnight. The tubes were then centrifuged at $12,000 \mathrm{rpm}$ for $25 \mathrm{~min}$ at $4{ }^{\circ} \mathrm{C}$. The RNA pellets were washed with $70 \%$ ethanol twice and re-suspended in $50 \mathrm{ul} \mathrm{DEPC-water.}$

mRNA (200 ng) was isolated from the total RNA sample using mRNA isolation kit (Stratagene) and subjected to cDNA library construction and sequencing on the GS FLX platform (Roche). We obtained 568,0911 reads with the average read length of $538 \mathrm{bp}$. The cDNA reads were cleaned (trim poly-A tail, remove short/repetitive/lowquality reads) by SeqClean [http://sourceforge.net/projects/seqclean/] and 535,728 reads were de novo assembled into 12,293 contigs by Newbler cDNA de novo assembler (Roche). The transcriptome was used to improve the annotation.

\section{Gene prediction and annotation}

MAKER (v.2.28) [71] was used as the main annotation pipeline for gene prediction and annotation. As part of MAKER, GlimmerHMM (v.3.0.1) [72], AUGUSTUS (v.2.6.1) [73, 74], SNAP (released 29/11/2013) [75], and GeneMark-ES fungal version [76] were used as ab initio gene predictors. The $a b$ initio SNAP was trained for a couple times within MAKER based on sequence similarity search via BLAST [77] and sequence alignment via Exonerate (v.2.2.0) [78] with default parameter settings, using 386,567 EST and 248,253 protein sequences of the order Hypocreales compiled from NCBI in October 2013, together with 10,848 assembled RNA-Seq transcripts, against the 598 scaffolds which were also masked by RepeatMasker (v.4.0.3) [79] together with Tandem Repeat Finder (TRF) (v.4.04) [80] and RMBlast (NCBI blast package of RepeatMasker), based on Repbase database (repeatmaskerlibraries-20130422.tar.gz; [81]). The transposable elements were extracted from the various types of masked repeats. The predicted transcripts were searched against the non-redundant protein database (NR) downloaded from NCBI on Feb 10, 2014. The BLAST results were then imported into BLAST2GO $[82,83]$ for Gene Ontology (GO), Enzyme, and KEGG pathway annotations. The tRNAs were predicted by the tRNAscan-SE (v.1.3.1) [84] and Aragorn (v.1.2.34) [85] 
and the protein secretion was predicted by SignalP 4.0 [12]. The completeness of genome assembly and gene annotation was assessed using BUSCO (v.1.1b1) [86], with the 598 scaffolds and predicted protein sequences of $O$. polyrhachis-furcata as respective inputs and the BUSCO's fungal dataset of 1438 benchmarking universal single-copy orthologs as profile.

\section{Orthology and phylogenomic analysis}

The standalone InParanoid (v.4.1) [38] and QuickParanoid [39] with default parameter settings were respectively used to identify and cluster the orthologous proteins of $O$. polyrhachis-furcata and the nineteen other taxa (the proteomes of these taxa were downloaded from UniProt: Additional file 10: Table S10). The concatenated 1,053 protein sequences conserved among all taxa were used as input of RAxML (v.8) [87] for building the phylogenomic tree using the Dayhoff model.

\section{Protein family classifications}

The potential pathogenic and virulence genes were identified by BLASTP against the pathogen-host interaction database (PHI-base) v.3.5 [13]. The families of proteases were identified by BLASTP against the peptidase database (MEROPS) release $9.10[88,89]$ with the E-value cutoff $<=1 \mathrm{E}-20$. The carbohydrate active enzymes; glycoside hydrolases (GHs), polysaccharide lyases (PLs), carbohydrate esterases (CEs), were classified by the CAZy database [90], of which protein sequences were manually compiled via a CAZy tool [91] kindly provided by Alexander Holm Viborg. The G-protein coupled receptors and transporters were classified based on BLASTP against the GPCRDB [92] (version 2013.09.26) and Transporter Classification Database (TCDB) (Last modified: July 15, 2011) [93], respectively. BLASTP against all specific protein databases except MEROPS used E-value cutoff $<=$ $1 \mathrm{E}-5$. Gene clusters and core genes for biosynthesis of secondary metabolites were identified by SMURF [55] and antiSMASH [94]. For phylogenetic analysis, sequences of all species hit with specific protein family (i.e., MEROPS: S08 and S53 for subtilisins) were extracted and multiple aligned using MAFFT v.7 [95]. RAxML version 8 [87] was then used to analyze the phylogenetic trees based on maximum likelihood and visualized by Dendroscope 3 [96].

\section{Additional files}

Additional file 1: Table S1. The number of genes for $\mathrm{PHI}$ genes family identified in O. polyrhachis-furcata and nineteen other fungi. (XLSX 252 kb)

Additional file 2: Table S2. The blast results for the protein-coding genes of O. polyrhachis-furcata against PHI database. (XLS 385 kb)

Additional file 3: Table S3. The number of subtilisins, trypsins, and aspartyl proteases identified in O. polyrhachis-furcata compared with nineteen other fungi. (XLSX $14 \mathrm{~kb}$ )
Additional file 4: Table S4. The number of genes following the MEROPS databases (peptidases) identified in O. polyrhachis-furcata, compared with the nineteen other fungi included in this study. (XLSX 50 kb)

Additional file 5: Table S5. The number of genes in different Glycoside Hydrolase $(\mathrm{GH})$ families, following the Carbohydrate-Active Enzymes Databases (CAZY), identified in O. polyrhachis-furcata and other nineteen fungi included in this study. (XLSX $21 \mathrm{~kb}$ )

Additional file 6: Table S6. The number of genes in different Polysaccharide Lyase (PL) families, following the Carbohydrate-Active Enzymes Databases (CAZY), identified in O. polyrhachis-furcata and other nineteen fungi included in this study. (XLSX $10 \mathrm{~kb}$ )

Additional file 7: Table S7. The number of genes in different Carbohydrate Esterase (CE) families, following the CarbohydrateActive Enzymes Databases (CAZY), identified in O. polyrhachis-furcata and other nineteen fungi included in this study. (XLSX $10 \mathrm{~kb}$ )

Additional file 8: Table S8. The number of bacterial-like toxins identified in O. polyrhachis-furcata compared with other entomopathogenic fungi. (XLSX $15 \mathrm{~kb}$ )

Additional file 9: Table S9. The number of transposable elements (TES) identified in OPF compared with other entomopathogenic fungi. The data of B. bassiana, C. militaris, M. robertsii, and M. acridum were obtained from Supplemental Table S2 of [3]. The data of $M$. anisopliae was obtained from [2]. The data of $O$. sinensis was obtained from [4]. (PDF $10 \mathrm{~kb}$ )

Additional file 10: Table S10. List of nineteen fungal species selected from UniProt for orthology and comparative analysis with 0 . polyrhachisfurcata BCC54312. (PDF 29 kb)

\section{Competing interests}

The authors declare that they have no competing interests.

\section{Authors' contribution}

DW carried out the annotation, analyses and discussion of the data, as well as drafting of the manuscript. NK carried out the collection of strains, molecular work and drafting of the manuscript and interpretation of the data. SI carried out the partial analyses of data and help in the annotation as well as discussion of the results and drafting the manuscript. ST carried out the genome sequencing and discussion of the results and drafting of the manuscript. DC carried out the transcriptomics work to improve the annotation. J J conceived and designed the study, carried out the collection of strains, participated in its design and helped draft the manuscript. LE participated in the design of the study, coordination and discussion of the results. All authors have participated sufficiently in the completion of the work, have read and approved the final manuscript.

\section{Acknowledgements}

This work was supported by the Platform Technology Management Section (grant number P-12-01036), National Center for Genetic Engineering and Biotechnology (BIOTEC), National Science and Technology Development Agency (NSTDA), Thailand. Mrs. Rachada Promhan is thanked for growing the fungus and maintaining the culture, Mrs. Suchada Mongkolsamrit and Ms. Kanoksri Tasanathai are thanked for their help in collecting the fungus. We also would like to thank the anonymous reviewers for their suggestions and comments to improve the manuscript.

\section{Author details}

${ }^{1}$ National Center for Genetic Engineering and Biotechnology, National Science and Technology Development Agency, 113 Thailand Science Park, Phahonyothin Rd., Khlong Neung, Khlong Luang 12120 Pathum Thani, Thailand. '2Department of Computer Engineering, Faculty of Engineering, Chulalongkorn University, Floor 17th, Building 4, Payathai Rd., Wangmai, Pathumwan 10330 Bangkok, Thailand.

Received: 13 July 2015 Accepted: 16 October 2015 Published online: 28 October 2015

\section{References}

1. Galagan JE, Henn MR, Ma LJ, Cuomo CA, Birren B. Genomics of the fungal kingdom: Insights into eukaryotic biology. Genome Res. 2005;15:1620-31. 
2. Gao Q, Jin K, Ying S-H, Zhang Y, Xiao G, Shang Y, et al. Genome sequencing and comparative transcriptomics of the model entomopathogenic fungi Metarhizium anisopliae and M. acridum. PLoS Genet. 2011;7, e1001264.

3. Xiao G, Ying SH, Zheng P, Wang ZL, Zhang S, Xie XQ, et al. Genomic perspectives on the evolution of fungal entomopathogenicity in Beauveria bassiana. Sci Rep. 2012;2:483.

4. Hu X, Zhang YJ, Xiao GH, Zheng P, Xia YL, Zhang XY, et al. Genome survey uncovers the secrets of sex and lifestyle in caterpillar fungus. Chin Sci Bull. 2013;58:2846-54

5. Zheng P, Xia Y, Xiao G, Xiong C, Hu X, Zhang S, et al. Genome sequence of the insect pathogenic fungus Cordyceps militaris, a valued traditional Chinese medicine. Genome Biol. 2011;12:R116.

6. Molnár I, Gibson DM, Krasnoff SB. Secondary metabolites from entomopathogenic Hypocrealean fungi. Nat Prod Rep. 2010;27:1241-75.

7. Anderson SB, Gerritsma S, Yusah KM, Mayntz D, Hywel-Jones NL, Billen J, et al. The life of a dead ant: the expression of adaptive extended phenotype. Am Nat. 2009;174:424-33.

8. Wang L, Zhang WM, Hu B, Chen YQ, Qu LH. Genetic variation of Cordyceps militaris and its allies based on phylogenetic analysis of rDNA ITS sequence data. Fungal Biol. 2008;31:147-55.

9. Quan QM, Chen LL, Wang X, Li S, Yang XL, Zhu YG, et al. Genetic diversity and distribution patterns of host insects of caterpillar fungus Ophiocordyceps sinensis in the Qinghai-Tibet Plateau. PLoS One. 2014;9, e92293.

10. Evans HC, Elliot SL, Hughes DP. Hidden diversity behind the Zombie-Ant Fungus Ophiocordyceps unilateralis: four new species described from Carpenter Ants in Minas Gerais. Brazil PLoS One. 2011;6, e17024.

11. Kobmoo N, Mongkolsamrit S, Tasanathai K, Thanakitpipattana D, Luangsaard JJ. Molecular phylogenies reveal host-specific divergence of Ophiocordyceps unilateralis sensu lato following its host ants. Mol Ecol. 2012;21:3022-31.

12. Petersen TN, Brunak S, von Heijne G, Nielsen H. SignalP 4.0: discriminating signal peptides from transmembrane regions. Nat Methods. 2011;8:785-6.

13. Winnenburg R, Baldwin TK, Urban M, Rawlings C, Köhler J, HammondKosack KE. PHI-base: a new database for pathogen host interactions. Nucleic Acids Res. 2006;34:D459-464.

14. Jeon J, Park S-Y, Chi M-H, Choi J, Park J, Rho H-S, et al. Genome-wide functional analysis of pathogenicity genes in the rice blast fungus. Nat Genet. 2007;39:561-5.

15. $\mathrm{Xu} J \mathrm{R}$, Staiger CJ, Hamer JE. Inactivation of the mitogen-activated protein kinase Mps1 from the rice blast fungus prevents penetration of host cells but allows activation of plant defense responses. Proc Natl Acad Sci U S A. 1998;95:12713-8.

16. Bean TP, Cools HJ, Lucas JA, Hawkins ND, Ward JL, Shaw MW, et al. Sterol content analysis suggests altered eburicol 14a-demethylase (CYP51) activity in isolates of Mycosphaerella graminicola adapted to azole fungicides. Microbiol Lett. 2009;296:266-73.

17. Xu L, Chen W. Random t-dna mutagenesis identifies a Cu/Zn superoxide dismutase gene as a virulence factor of Sclerotinia sclerotiorum. Mol Plant Microbe Interact. 2013;26:431-41.

18. Scheffer J, Chen C, Heidrich P, Dickman MB, Tudzynski P. A CDC42 Homologue in Claviceps pupurea is involved in vegetative differentiation and is essential for pathogenicity. Eukaryot Cell. 2005;4:1228-38.

19. Wang C, Zhang S, Hou R, Zhao Z, Zheng Q, Xu Q, et al. Functional analysis of the kinome of the Wheat Scab Fungus Fusarium graminearum. Plos Pathogens. 2011;7, e1002460.

20. Chang YC, Miller GF, Kwon-Chung KJ. Importance of a developmentally regulated pheromone receptor of Cryptococcus neoformans for virulence. Infect Immun. 2003;71:4953-60.

21. Zhang H, Tang W, Liu K, Huang Q, Zhang X, Yan X, et al. Eight RGS and RGS-like proteins orchestrate growth, differentiation, and pathogenicity of Magnaporthe oryzae. PLoS Pathog. 2011;7, e1002450

22. Lanver D, Mendoza-mendoza A, Brachmann A, Kahmann R. Sho1 and Msb2related proteins regulate appressorium development in the smut fungus Ustilago maydis. Plant Cell. 2010;22:2085-101.

23. Staats M, VAN Baarlen P, Schouten A, VAN Kan JA. Functional analysis of NLP genes from Botrytis elliptica. Mol Plant Pathol. 2007;8:209-14.

24. Hu W, Sillaots S, Lemieux S, Davison J, Kauffman S, Breton A, et al. Essentia gene identification and drug target prioritization in Aspergillus fumigatus. PLoS Pathog. 2007;3, e24.
25. Shen $Y$, Sharma $P$, da Silva FG, Ronald P. The Xanthomonas oryzae pv. Oryzae raxP and raxQ genes encode an ATP sulphurylase and adenosine-5'phosphosulphate kinase that are require for QvrXa21 avirulence activity. Mol Microbiol. 2002:44:37-48.

26. Koenraadt H, Somerville SC, Jones AL. Characterization of mutations in the beta-tubulin gene of benomyl-resistant field Straits of Venturia inaequalis and other plant pathogenic fungi. Mol Plant Pathol. 1992;82:1348-54.

27. Ma Z, Yoshimura MA, Michqilides TJ. Identification and characterization of benzimidazole resistance in Monilinia fructicola from stone fruit orchards in California. Appl Environ Microbiol. 2003;69:7145-52.

28. Hollomon DW, Butters JA, Barker H, Hall L. Fungal beta-tubulin, expressed as a fusion protein, binds benzimidazole and phenylcarbamate fungicides. Antimicrob Agents Chemother. 1998;42:2171-3.

29. Wahl R, Wippel K, Goos S, Kämper J, Sauer N. A novel high-affinity sucrose transporter is required for avirulence of the plant pathogen Ustilago maydis. PLOS Biol. 2010;8, e1000303.

30. Yamada-Okabe T, Yamada-Okabe H. Characterization of the CaNAG3, CaNAG4, and CaNAG6 genes of the pathogenic fungus Candida albicans: possible involvement of these genes in the susceptibilities of cytotoxic agents. FEMS Microbiol Lett. 2002;212:15-21.

31. Bayry J, Aimanianda V, Guijarro JI, Sunde M, Latgé JP. Hydrophobins-Unique fungal proteins. PLoS Pathol. 2013;8, e1002700.

32. St Leger RJ, Staples RC, Roberts DW. Cloning and regulatory analysis of starvation-stress gene, ssgA, encoding a hydrophobin-like protein from the entomopathogenic fungus, Metarhizium anisopliae. Gene. 1992;120:119-24.

33. Zhang S, Xia YX, Kim B, Keyhani NO. Two hydrophobins are involved in fungal spore coat rodlet layer assembly and each play distinct roles in surface interactions, development and pathogenesis in the entomopathogenic fungus, Beauveria bassiana. Mol Microbiol. 2011;80:811-26.

34. Cho E-M, Kirkland BH, Holder DJ, Keyhani NO. Phage display cDNA cloning and expression analysis of hydrophobins from the entomopathogenic fungus Beauveria (Cordyceps) bassiana. Microbiology. 2007;153:3438-47.

35. Sevim A, Donzelli BGG, Wu D, Demirbag Z, Gibson DM, Turgeon BG. Hydrophobin genes of the entomopathogenic fungus, Metarhizium brunneum, are differentially expressed and corresponding mutants are decreased in virulence. Curr Genet. 2012;58:79-92.

36. Wang C, St Leger RJ. The MAD1 adhesin of Metarhizium anisopliae links adhesion with blastospore production and virulence to insects, and the MAD2 adhesin enables attachment to plants. Eukaryot Cell. 2007;6:808-16.

37. Bagga S, Hu G, Screen SE, St Leger RJ. Reconstructing the diversification of subtilisins in the pathogenic fungus Metarhizium anisopliae. Gene. 2007;324:159-69.

38. Ostlund G, Schmitt T, Forslund K, Köstler T, Messina DN, Roopra S, et al. InParanoid 7: new algorithms and tools for eukaryotic orthology analysis. Nucleic Acids Res. 2010;38:D196-203.

39. QuickParanoid. http://pl.postech.ac.kr/QuickParanoid/

40. da Silva MV, Santi L, Staats CC, da Costa AM, Colodel EM, Driemeier D, et al. Cuticle-induced endo/exoacting chitinase CHIT30 from Metarhizium anisopliae is encoded by an ortholog of the chi3 gene. Res in Microbiol. 2005;156:382-92.

41. Fang W, Leng B, Xiao Y, Jin K, Ma J, Fan Y, et al. Cloning of Beauveria bassiana chitinase gene Bbchit1 and its application to improve fungal strain virulence. Appl Environ Microb. 2005;71:363-70.

42. Staats CC, Kmetzsch L, Lubeck I, Junges A, Vainstein MH, Schrank A. Metarhizium anisopliae chitinase CHIT30 is involved in heat-shock stress and contributes to virulence against Dysdercus peruvianus. Fungal Biol. 2013;117:137-44.

43. de Wit PJGM, van der Burgt A, Ökmen B, Stergiopoulos I, Abd-Elsalam KA, Aerts $A L$, et al. The genomes of the fungal plant pathogens Cladosporium fulvum and Dothistroma septosporum reveal adaptation to different hosts and lifestyles but also signatures of common ancestry. PLoS Genet. 2012;8, e1003088

44. Kulkarni RD, Thon MR, Pan H, Dean RA. Novel G-protein-coupled receptor-like proteins in the plant pathogenic fungus Magnaporthe grisea. Genome Biol. 2005;6:R24.

45. DeZwaan TM, Carroll AM, Valent B, Sweigard JA. Magnaporthe grisea pth $11 p$ is a novel plasma membrane protein that mediates appressorium differentiation in response to inductive substrate cues. Plant Cell. 1999;11:2013-30.

46. Lafon A, Han KH, Seo JA, Yu JH, D'Enfert C. G-protein and CAMP-mediated signaling in aspergilli: a genomic perspective. Fungal Genet Biol. 2006;B 43:490-502.

47. Solomon PS, Tan K-C, Sanchez P, Cooper RM, Oliver RP. The disruption of a Galpha subunit sheds new light on the pathogenicity of Stagonospora nodorum on wheat. Mol Plant Microb Interact. 2004;17:456-66. 
48. Motoyama T, Kadokura K, Ohira T, Ichiishi A, Fujimura M, Yamaguchi I, et al. A two-component histidine kinase of the rice blast fungus is involved in osmotic stress response and fungicide action. Fungal Genet Biol. 2005;B 42:200-12.

49. Ochiai N, Tokai T, Nishiuchi T, Takahashi-Ando N, Fujimura M, Kimura M, et al. Involvement of the osmosensor histidine kinase and osmotic stress-activated protein kinases in the regulation of secondary metabolism in Fusarium graminearum. Biochem Biophys Res Commun. 2007;363:639-44.

50. Dongo A, Bataillé-Simoneau N, Campion C, Guillemette T, Hamon B, lacomiVasilescu B, et al. The group III two-component histidine kinase of filamentous fungi is involved in the fungicidal activity of the bacterial polyketide ambruticin. Appl Environ Microb. 2009;75:127-34.

51. Alex LA, Borkovich KA, Simon MI. Hyphal development in Neurospora crassa: involvement of a two-component histidine kinase. Proc Natl Acad Sci U S A. 1996:93:3416-21.

52. Viaud M, Fillinger S, Liu W, Polepalli JS, LE Pêcheur P, Kunduru AR, et al. A class III histidine kinase acts as a novel virulence factor in Botrytis cinerea. Mol Plant Microb Interact. 2006;19:1042-50.

53. Cui W, Beever RE, Parkes SL, Weeds PL, Templeton MD. An osmosensing histidine kinase mediates dicarboximide fungicide resistance in Botryotinia fuckeliana (Botrytis cinerea). Fungal Genet and Biol. 2002;B 36:187-98.

54. Avenot H, Simoneau P, lacomi-Vasilescu B, Bataillé-Simoneau N. Characterization of mutations in the two-component histidine kinase gene AbNIK1 from Alternaria brassicicola that confer high dicarboximide and phenylpyrrole resistance. Curr Genet. 2005:47:234-43.

55. Khaldi N, Khaldi N, Seifuddin FT, Seifuddin FT, Turner G, Fedorova ND. SMURF: Genomic mapping of fungal secondary metabolite clusters. Fungal Genet and Biol. 2010;B 47:736-41.

56. Sondergaard TE, Hansen FT, Purup S, Nielsen AK, Bonefeld-Jørgensen EC, Giese $\mathrm{H}$, et al. Fusarin $\mathrm{C}$ acts like an estrogenic agonist and stimulates breast cancer cells in vitro. Toxicol Lett. 2011;205:116-21.

57. Niehaus E-M, Kleigrewe K, Wiemann P, Studt L, Sieber CMK, Connolly LR, et al. Genetic manipulation of the Fusarium fujikuroi fusarin gene cluster yields insight into the complex regulation and fusarin biosynthetic pathway. Chem Biol. 2013;20:1055-66.

58 Tanaka A, Tapper BA, Popay A, Parker EJ, Scott B. A symbiosis expressed non-ribosomal peptide synthetase from a mutualistic fungal endophyte of perennial ryegrass confers protection to the symbiotum from insect herbivory. Mol Microbiol. 2005;57:1036-50.

59. Blin K, Medema MH, Kazempour D, Fischbach MA, Breitling R, Takano E, et al. antiSMASH 2.0-a versatile platform for genome mining of secondary metabolite producers. Nucleic Acids Res. 2013;41:W204-212.

60. Karolewiez A, Geisen R. Cloning a part of the ochratoxin A biosynthetic gene cluster of Penicillium nordicum and characterization of the ochratoxin polyketide synthase gene. Syst Appl Microbiol. 2005;28:588-95.

61. Ownley BH, Griffin MR, Klingeman WE, Gwinn KD, Moulton JK, Pereira RM. Beauveria bassiana: Endophytic colonization and plant disease control. J Invertebre Pathol. 2008;98:267-70.

62. Batta YA. Efficacy of endophytic and applied Metarhizium anisopliae (Metch.) Sorokin (Ascomycota: Hypocreales) against larvae of Plutella xylostella L. (Yponomeutidae:Lepidoptera) infesting Brassica napus plants. Crop Prot. 2013;44:128-34

63. Bye NJ, Charnley AK. Regulation of cuticle-degrading subtilisin proteases from the entomopathogenic fungi, Lecanicillium spp: implications for host specificity. Arch Microbiol. 2008;189:81-92.

64. Wang S, Leclerque A, Pava-Ripoll M, Fang W, St Leger RJ. Comparative genomics using microarrays reveals divergence and loss of virulence-associated genes in host-specific strains of the insect pathogen Metarhizium anisopliae. Eukaryot Cell. 2009;8:888-98.

65. Grandaubert J, Balesdent MH, Rouxel T. Evolutionary and adaptive role of transposable elements in fungal genomes. In: Martin FM, editor. Fungi. London: Academic; 2014. p. 79-107.

66. Zhang L, Yan $L$, Jiang J, Wang $Y$, Jiang $Y$, Yan $T$, et al. The structure and retrotransposition mechanism of LTR-retrotransposons in the asexual yeast Candida albicans. Virulence. 2015;5:655-64.

67. Grandaubert J, Lowe RGT, Soyer JL, Schoch CL, Van de Wouw AP, Fudal I, et al. Transposable element-assisted evolution and adaptation to host plant within the Leptosphaeria maculans-Leptosphaeria biglobosa species complex of fungal pathogens. BMC Genomics. 2014;15:891.
68. Kasuga T, Kozanitas M, Bui M, Büberli D, Rizzo DM, Garbelotto M. Phenotypic diversification is associated with host-induced transposon derepression in the Sudden Oak Death pathogen Phytophthora ramorum. PLoS One. 2012;7, e34728.

69. Wongsa P, Tasanatai K, Watts P, Hywel-Jones N. Isolation and in vitro cultivation of the insect pathogenic fungus Cordyceps unilateralis. Mycol Res. 2005;109:936-40.

70. Boetzer M, Henkel CV, Jansen HJ, Butler D, Pirovano W. Scaffolding preassembled contigs using SSPACE. Bioinformatics. 2011;27:578-9.

71. Cantarel BL, Korf I, Robb SMC, Parra G, Ross E, Moore B, et al. MAKER: an easy-to-use annotation pipeline designed for emerging model organism genomes. Genome Res. 2008;18:188-96.

72. Majoros WH, Pertea M, Salzberg SL. TigrScan and GlimmerHMM: two open source ab initio eukaryotic gene-finders. Bioinformatics. 2004;20:2878-9

73. Stanke M, Waack S. Gene prediction with a hidden Markov model and a new intron submodel. Bioinformatics. 2003;19 Suppl 2:ii215-225.

74. Stanke M, Schöffmann O, Morgenstern B, Waack S. Gene prediction in eukaryotes with a generalized hidden Markov model that uses hints from external sources. BMC Bioinformatics. 2006;7:62.

75. Korf I. Gene finding in novel genomes. BMC Bioinformatics. 2004;5:59.

76. Ter-Hovhannisyan V, Lomsadze A, Chernoff YO, Borodovsky M. Gene prediction in novel fungal genomes using an ab initio algorithm with unsupervised training. Genome Res. 2008;18:1979-90.

77. Altschul SF, Gish W, Miller W, Myers EW, Lipman DJ. Basic local alignment search tool. J Mol Biol. 1990;215:403-10.

78. Slater GSC, Birney E. Automated generation of heuristics for biological sequence comparison. BMC Bioinformatics. 2005;6:31.

79. Smit AFA, Hubley R, Green P. RepeatMasker. http://repeatmasker.org

80. Benson G. Tandem repeats finder: a program to analyze DNA sequences. Nucleic Acids Res. 1999;27:573-80.

81. RepBase. http://www.girinst.org/repbase

82. Conesa A, Götz S, García-Gómez JM, Terol J, Talón M, Robles M. Blast2GO: a universal tool for annotation, visualization and analysis in functional genomics research. Bioinformatics. 2005;21:3674-6.

83. Götz S, García-Gómez JM, Terol J, Williams TD, Nagaraj SH, Nueda MJ, et al. High-throughput functional annotation and data mining with the Blast2GO suite. Nucleic Acids Res. 2008;36:3420-35.

84. Lowe TM, Eddy SR. tRNAscan-SE: a program for improved detection of transfer RNA genes in genomic sequence. Nucleic Acids Res. 1997;25:955-64

85. Laslett D. ARAGORN, a program to detect tRNA genes and tmRNA genes in nucleotide sequences. Nucleic Acids Res. 2004;32:11-6.

86. Simão FA, Waterhouse RM, loannidis P, Kriventseva EV, Zdobnov EM BUSCO: assessing genome assembly and annotation completeness with single-copy orthologs. 2015;doi:10.1093/bioinformatics/btv351

87 Stamatakis A. RAxML version 8: a tool for phylogenetic analysis and post-analysis of large phylogenies. Bioinformatics. 2014;30:1312-3.

88. Rawlings ND, Morton FR, Kok CY, Kong J, Barrett AJ. MEROPS: the peptidase database. Nucleic Acids Res. 2008;36:D320-325.

89. Rawlings ND, Waller M, Barrett AJ, Bateman A. MEROPS: the database of proteolytic enzymes, their substrates and inhibitors. Nucleic Acids Res. 2014:42:D503-9.

90. Cantarel BL, Cantarel BL, Coutinho PM, Coutinho PM, Rancurel C, Henrissat B. The Carbohydrate-Active EnZymes database (CAZy): an expert resource for Glycogenomics. Nucleic Acids Res. 2009;37:D233-8.

91. CAZy: Extract sequences. http://www.ahv.dk/index.php/cazy-extract-sequences

92. Vroling B, Vroling B, Sanders M, Sanders M, Baakman C, Vriend G. GPCRDB: information system for $G$ protein-coupled receptors. Nucleic Acids Res. 2011;39:D309-319.

93. Saier MH, Tran CV, Barabote RD. TCDB: the Transporter Classification Database for membrane transport protein analyses and information. Nucleic Acids Res. 2006:34:D181-186.

94. Medema MH, Blin K, Cimermancic P, de Jager V, Zakrzewski P, Fischbach MA, et al. antiSMASH: rapid identification, annotation and analysis of secondary metabolite biosynthesis gene clusters in bacterial and fungal genome sequences. Nucleic Acids Res. 2011;39:W339-346.

95. Katoh K, Standley DM. MAFFT multiple sequence software version 7: improvements in performance and usability. Mol Biol Evol. 2013;30:772-80

96. Huson DH, Scornavacca C. Dendroscope 3: an interactive tool for rooted phylogenetic trees and networks. Syst Biol. 2012;61:1061-7. 